\title{
The Role of L-Glutamine in the Phenotypic Change of a rod Mutant Derived from Bacillus subtilis 168
}

\author{
By H. J. ROGERS AND MOYRA MCCONNELL \\ National Institute for Medical Research, Mill Hill, London, N.W.7 \\ (Accepted for publication 24 December 1969)
}

\begin{abstract}
SUMMARY
The morphological mutant rod-4 derived from Bacillus subtilis I 68 trp can be changed from a round form to a rod by the addition to the growth medium of sufficient acid-hydrolysate of casein. The hydrolysate can be replaced by a mixture of amino acids, and the only individual amino acids giving similar results are L-glutamic acid, L-proline, L-arginine and L-ornithine. Since the lag in the action of L-glutamate was less than for the other amino acids, this amino acid is likely to be responsible for the effect of the mixture. Experiments with the L-glutamine analogue, $\gamma$-L-glutamylhydrazide, strongly suggest that L-glutamine is the active metabolite rather than the amino acid itself. The correcting effect of high ionic strengths of the growth medium on the morphology of this mutant seems to be mostly due to the increased effectiveness of L-glutamate or L-glutamine in the presence of high concentrations of salts.
\end{abstract}

\section{INTRODUCTION}

In previous papers (Rogers, McConnell \& Burdett, I968, I970) the isolation and characterization of rod mutants from strains of Bacillus subtilis and B. licheniformis were described. It was shown that the phenotypic transformation from a collection of coccal bodies to rods could be effected in one class of mutant, either by high ionic strength of the medium or by an increase in its organic- $\mathrm{N}$ content. The present paper examines the nature of the metabolite present in the richer medium which is necessary for the transformation of one of the mutants, $\operatorname{rod}-4$, the most easily transformed of the mutants studied.

\section{METHODS}

Micro-organisms. The mutant rod-4 derived from Bacillus subtilis 168 trp was stored at room temperature in the dried state and was revived as required by mixing with minimal liquid medium and inoculating a $0 . \mathrm{I} \%(\mathrm{w} / \mathrm{v})$ casein hydrolysate + salts + glucose agar plate with a suspension. The mutant was subcultured every few days on the $0.1 \%$ casein hydrolysate + salts + glucose agar medium previously described (Rogers et al. 1970); after overnight incubation at $35^{\circ}$ the plates were stored at room temperature. The parent strain B. subtilis $168 \operatorname{trp}$ was stored as a spore suspension.

Media. The basal liquid minimal medium was as previously described (Rogers et al. 1970). The acid-hydrolysed casein used was the dried Difco product.

Chemicals. The L-amino acids used were obtained from British Drug Houses and were shown to be chromatographically homogeneous when examined by one-dimensional paper chromatography with butanol + acetic acid + water $(63+10+27$ by vol., 
upper phase) as solvent. Two specimens of $\gamma$-L-glutamylhydrazide were used. One was a specimen synthesized and given us by Dr H. R. Perkins (Chemistry Division, this Institute); the other was obtained from the Mann Research Laboratories, New York, U.S.A.

\section{RESULTS}

The effect of acid hydrolysed casein on the morphology

Liquid minimal medium was supplemented with increasing concentrations of casein hydrolysate and inoculated with a loopful of a suspension of rod-4 bacteria. The suspension was made by taking 3 or 4 colonies from an overnight culture of rod-4 grown on the surface of the usual $0 \cdot \mathrm{I} \%(\mathrm{w} / \mathrm{v})$ casein hydrolysate + salts + glucose agar medium and emulsifying them in the minimal liquid medium. The cultures were incubated overnight at $35^{\circ}$ with shaking. At concentrations above about $0.2 \%$ casein hydrolysate the bacteria appeared as rods, whilst at lower concentrations most of the bacteria were round in form (Table I). The acid-hydrolysed casein could be replaced at about the same concentration by a mixture of L-amino acids (Table I); the relative concentrations of the amino acids in the mixture were about the same as those present in casein. It thus appeared that one or more amino acids were responsible for the morphological change.

Table I. Bacillus subtilis I68: effect of increasing concentrations of casein hydrolysate and amino acid mixtures on the morphology of rod-4

The cultures ( $10 \mathrm{ml}$.) were incubated for $18 \mathrm{hr}$ at $35^{\circ}$ shaken in $50 \mathrm{ml}$. flasks. The basal minimal medium was as described by Rogers et al. (1970).

Concentration of
casein hydrolysate
$(\%)$
0
0.05
0.1
0.2
0.5

\begin{tabular}{|c|c|}
\hline \multicolumn{2}{|c|}{ Morphology } \\
\hline In casein hydrolysate & In amino acid mixture \\
\hline Round & Round \\
\hline Round & Round \\
\hline Round & Round and oval \\
\hline Short rods & Long rods \\
\hline Short and long rods & Long rods \\
\hline
\end{tabular}

On repeated tests of the lower concentrations of casein hydrolysate or amino acid mixture, considerable variability was found in the morphology of the bacteria when cultures were first examined at $18 \mathrm{hr}$. Occasionally the bacteria appeared as rods at this time, but on further incubation (up to $48 \mathrm{hr}$ ) as round or oval forms. Examination every few hours after inoculation showed that a definite cycle of events frequently occurred in liquid culture, and always on the surface of solid media. Groups of the round forms first threw out filaments consisting of cells of five or ten times the length of the cells in the parent culture. These filaments extended in length to a degree which was related to the concentration of casein hydrolysate or amino acid mixture in the growth medium. Plate I shows such filaments photographed as part of a time-lapse film of the process (the film was made in collaboration with Mr M. R. Young of this Institute). In liquid medium very long filaments were occasionally not produced, but rods were broken off while the filaments were still quite short. This difference appeared to be correlated with the degree of motility of the resultant rods: when they were motile, long filaments were sometimes not formed. Eventually the extension of the 
chains of very long forms slowed or stopped and the forms divided and separated to give rods. When very low concentrations of amino acids were originally present in the medium, swellings appeared in the filaments and round forms appeared.

\section{Analysis of the effects of individual amino acids}

Since an amino acid mixture could substitute for acid-hydrolysed casein, the possibility that one particular amino acid or metabolically related group of amino acids was responsible for converting the round forms through filaments to rods was tested. The examination of cultures at a single time interval was likely to be unreliable,

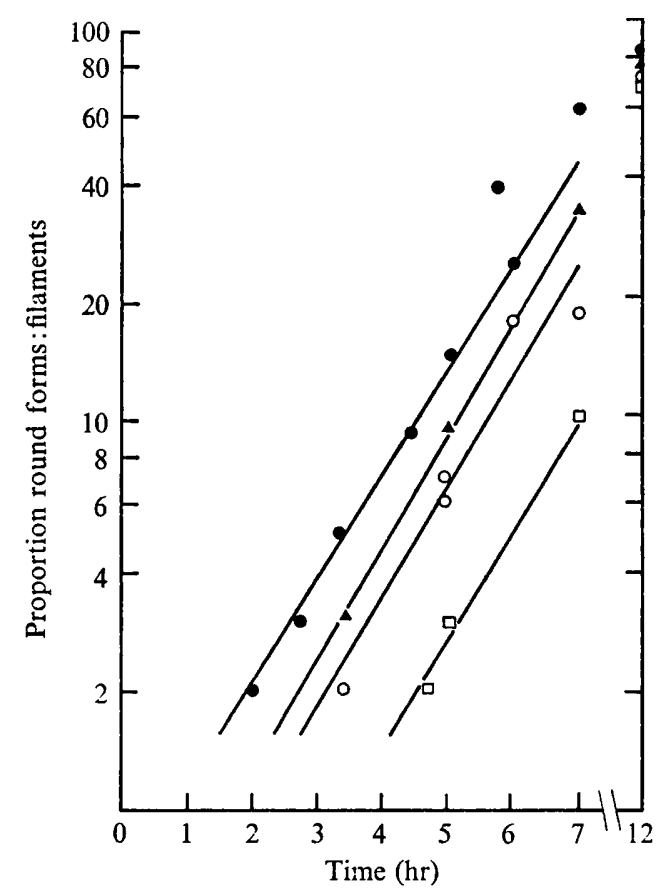

Fig. I. The effect of $\mathrm{L}$-amino acids on the appearance of filaments. The minimal liquid medium ( $10 \mathrm{ml}$. in $50 \mathrm{ml}$. flasks) supplemented with $0.2 \%$ of L-amino acids and inoculated with $0.5 \mathrm{ml}$. of a suspension of the rod-4 mutant. The inoculum was prepared by suspending the growth from an $18 \mathrm{hr}$ culture on a $2.5 \mathrm{in}$. Petri dish of the minimal $+0.1 \%$ casein hydrolysate + glucose agar medium (Rogers et al. 1970). The suspension (IO ml.) was centrifuged and the deposited bacteria washed once and then suspended in $5.0 \mathrm{ml}$. minimal medium. The original suspending fluid and washing fluids were minimal liquid medium. Such an inoculum gave a final concentration equivalent to $10^{5}$ viable units $/ \mathrm{ml}$. culture. Incubation was at $35^{\circ}$ with shaking. arginine.

in the absence of knowledge of both the time and the concentration for any amino acid required for the filaments to divide into recognizable rods. The following technique was therefore used: flasks containing the basal liquid minimal medium were supplemented with the various L-amino acids, heavily inoculated and incubation continued, loopfuls of the culture being removed at intervals of a few hours. These samples were examined with the phase-contrast microscope $(\times 200)$ and the number 
of groups of round forms showing the beginning of filament formation was measured as a percentage of the total. One hundred or more groups of organisms were counted for each sample. The increase in this proportion by using group A amino acids appeared to be exponential and the doubling-times were about the same for L-glutamic acid, L-proline, L-ornithine and L-arginine (Fig. I). The following amino acids (group B) had no influence in producing filaments from the round forms: L-valine, L-methionine, L-leucine, L-isoleucine, L-lysine, L-phenylalanine, L-threonine, L-cystine, L-tyrosine, L-tryptophan (increased concentration) and glycine. The amino acids L-alanine, L-aspartic acid and meso-2,6-diaminopimelic acid (group C) gave variable results. Sometimes this latter group of amino acids gave rise to the start of filaments in up to $60 \%$ of the groups of micro-organisms; these never became very long but rapidly divided and rounded up. In other experiments L-alanine and meso-2,6-diaminopimelic acid produced no filaments at all, and L-aspartate produced only 20 to $50 \%$. The main difference between the effect of amino acids in group $\mathrm{A}$ and group $\mathrm{C}$ was that whereas at a final concentration in the growth medium of $0.2 \%$ all group $\mathrm{A}$ amino acids led to the maintenance of the rod form after $\mathrm{I} 8$ to $24 \mathrm{hr}$ incubation at $35^{\circ}$, group C amino acids never did.

Table 2. Bacillus subtilis I68: effect of different concentrations of sodium L-glutamate added to liquid and solidified minimal-glucose medium upon the morphology of rod-4

The liquid cultures ( $10 \mathrm{ml}$.) were grown (shaken) for $\mathrm{I} 8 \mathrm{hr}$ at $35^{\circ}$ and were in $50 \mathrm{ml}$. flasks. The solid media were incubated at $35^{\circ}$ for the same time. The liquid and solid basal minimal media were as described by Rogers et al. (1970). No casein hydrolysate was present in the basal agar medium.

\begin{tabular}{|c|}
\hline $\begin{array}{c}\text { Concentration } \\
\text { of } \mathrm{L} \text {-glutamate } \\
(\%)\end{array}$ \\
\hline 0.005 \\
\hline 0.01 \\
\hline 0.02 \\
\hline 0.04 \\
\hline $0 \cdot 10$ \\
\hline 0.20 \\
\hline
\end{tabular}

\begin{tabular}{ll}
\multicolumn{2}{c}{ Morphological form } \\
Liquid culture & Solid medium \\
Round & Round \\
Round + rod & Round \\
Round + rod & Round + rod \\
Round + rod & Round +rod \\
Rod & Rod \\
Not done & Rod
\end{tabular}

The amino acids in group A are all on the direct path for the metabolism of glutamic acid. From the shorter delay in the appearance of filaments when L-glutamic acid itself was added, it was assumed that this amino acid was principally responsible for the effect of the amino acid mixture. Variation of the concentration of L-glutamic acid showed that increases between $0 . \mathrm{I}$ and $\mathrm{I} \cdot 0 \%$ led to increases in the rate at which filamented groups of round forms began to appear. When shaken liquid cultures and cultures on solid agar medium supplemented with L-glutamate were examined after I $8 \mathrm{hr}$ at $35^{\circ}$, the results shown in Table 2 were obtained. D-Glutamic acid, in contrast, was somewhat growth-inhibitory, and at no concentration between 0.02 and $0.2 \%$ did it convert the round forms to rods in $24 \mathrm{hr}$, and no filamentation was seen.

\section{Interrelationships between salt concentration and glutamic acid}

The observation of Rogers et al. (1968) was that the class of mutants which includes rod-4 grew as rods at high salt concentrations on minimal salts agar medium, whether or not casein hydrolysate was present. The casein hydrolysate was usually included to 
avoid the long periods of incubation necessary for growth of the mutants on unsupplemented minimal salts media. The interrelationship between the presence of salt and of casein hydrolysate or glutamic acid in liquid media was next examined.

The presence or absence of $0.8 \mathrm{M}$-sodium chloride in the medium was not relevant to the final morphology of the mutant grown in minimal liquid medium. When the mutant was subcultured into liquid minimal medium containing $0.8 \mathrm{M}$-sodium chloride but no Na L-glutamate the results shown in Table 3 were obtained. The essential rod-

\section{Table 3. Bacillus subtilis I68: effect of $\mathrm{NaCl}$ and sodium L-glutamate on the growth of rod-4 in liquid medium}

The cultures ( $10 \mathrm{ml}$.) were in shaken $50 \mathrm{ml}$. flasks incubated at $35^{\circ}$. Inoculated from solid medium with no added sodium chloride. The basal liquid medium was as in the previous experiments.

\begin{tabular}{|c|c|c|c|c|c|}
\hline \multirow[b]{2}{*}{ Medium } & \multirow{2}{*}{$\begin{array}{l}\text { Growth } \\
(24 \mathrm{hr})\end{array}$} & \\
\hline & & $4 \mathrm{hr}$ & $6 \mathrm{hr}$ & II hr & $24 \mathrm{hr}$ \\
\hline $\begin{array}{l}\text { Minimal } \\
\text { Minimal }+0.8 \mathrm{M}-\mathrm{NaCl} \\
\text { Minimal }+0 . \mathrm{I} \% \text { glutamic acid } \\
\text { Minimal }+0 . \mathrm{I} \% \text { glutamic acid }+ \\
0.8 \mathrm{M}-\mathrm{NaCl}\end{array}$ & $\begin{array}{l}++ \\
+ \\
++ \\
++\end{array}$ & $\begin{array}{l}\text { Round } \\
\text { Round } \\
\text { Round } \\
\text { Rods }\end{array}$ & $\begin{array}{l}\text { Round } \\
\text { Not done } \\
\text { Round + rods } \\
\text { Rods }\end{array}$ & $\begin{array}{l}\text { Round } \\
\text { Not done } \\
\text { Round + rods } \\
\text { Rods }\end{array}$ & $\begin{array}{l}\text { Round } \\
\text { Round } \\
\text { Round } \\
\text { Rods }\end{array}$ \\
\hline \multicolumn{6}{|c|}{ Inoculated from solid medium $+0.8 \mathrm{M}-\mathrm{NaCl}$ : } \\
\hline & $+t$ & Rod & Not & & \\
\hline Minima & ++ & Ro & No & Rods & Round \\
\hline Minima & +++ & Ro & No & Rods & \\
\hline $\begin{array}{l}\text { Minimal }+0.1 \% \text { glutamic acid }+ \\
0.8 \mathrm{M}-\mathrm{NaCl}\end{array}$ & +++ & Rods & Not done & Rods & Rods \\
\hline
\end{tabular}

forming factor in the liquid medium was the presence or absence of $\mathrm{Na}$ L-glutamate. In the absence of the amino acid, the addition of $0.8 \mathrm{M}$-sodium chloride did not effect the conversion to rods but only decreased the amount of growth. Moreover, when the inoculum was in the form of rods, being taken from the $0.1 \%$ casein-hydrolysate medium containing $0.8 \mathrm{M}-\mathrm{NaCl}$, it changed to a round form in $0.8 \mathrm{M}-\mathrm{NaCl}$ when glutamate was not present. High ionic strength in the medium considerably increased the effectiveness of the glutamate so that even at $0.01 \%$ the mutant grew as a rod and remained so after $24 \mathrm{hr}$ of incubation (Table 4). In media not containing $0.8 \mathrm{M}-\mathrm{NaCl}$ complete conversion (maintained for $24 \mathrm{hr}$ ) was not effected until a concentration of $0.1 \% \mathrm{Na}$ L-glutamate was reached. Even at this concentration the results were variable (e.g. see Table 3 , line 3 ) and $0.2 \%$ was required for the organism certainly to remain as a rod after $24 \mathrm{hr}$ of incubation. The effect of high ionic strength seemed to be in preventing the subdivision and rounding-up of the long cells formed at first, during prolonged incubation, rather than in altering the effect of L-glutamate or in starting the conversion of the round form into a filament. The reason for the difference between the solid and liquid media is not understood.

\section{The relative importance of $L$-glutamic acid and $L$-glutamine}

A relatively high concentration of $\mathrm{L}$-glutamic acid was required to effect and maintain the change from round forms to rods. It therefore seemed possible that L-glutamine formed from the added L-glutamic acid and the $\mathrm{NH}_{4}{ }^{+}$in the medium was responsible rather than the amino acid itself. To test this, the technique for measuring the increase 
in groups of round forms forming filaments was applied to cultures in which mixtures of $\mathrm{Na} \mathrm{L}$-glutamate and $\gamma$-L-glutamylhydrazide were added to the basal minimal medium. $\gamma$-L-Glutamylhydrazide has been shown (McIlwain, Roper \& Hughes, 1948) to inhibit the hydrolysis of glutamine to ammonia and glutamic acid, and to inhibit the growth of Streptococcus haemolyticus and S. faecalis competitively with L-glutamine.

Table 4. Bacillus subtilis I68: effect of different concentrations of Na L-glutamate upon the morphology of rod-4 growing with and without the addition of $0.8 \mathrm{M}-\mathrm{NaCl}$

The cultures ( $10 \mathrm{ml}$.) were in $50 \mathrm{ml}$. flasks and were incubated at $35^{\circ}$ with shaking. The cultures were also inspected with the phase-contrast microscope at $4 \mathrm{hr}, 6 \mathrm{hr}$ and I I hr.

\begin{tabular}{|c|c|c|}
\hline \multirow{2}{*}{$\begin{array}{c}\mathrm{Na} \text { L-glutamate } \\
\text { concentration } \\
(\%)\end{array}$} & \multicolumn{2}{|c|}{ Morphology at $24 \mathrm{hr}$} \\
\hline & $+0.8 \mathrm{M}-\mathrm{NaCl}$ & No added $\mathrm{NaCl}$ \\
\hline 0 & Round & Round \\
\hline 0.01 & Rod (short)* & Round $†$ \\
\hline 0.03 & Rod* & Round $\uparrow$ \\
\hline 0.05 & Rod* & Round + rod $\dagger$ \\
\hline $0 \cdot 10$ & Rod (variable)* & Rod \\
\hline 0.20 & Rod* & Rod \\
\hline 0.50 & Rod (long)* & Rod \\
\hline
\end{tabular}

* At $6 \mathrm{hr}$ showed long twisted rods.

† About $40 \%$ of the round-form groups showed the beginnings of filamentation at $6 \mathrm{hr}$.

Table 5. Bacillus subtilis 168: effect of $\gamma$-L-glutamylhydrazide on morphological change of rod-4

Two of the readings of the experiment are recorded. The cultures ( $10 \mathrm{ml}$.) were contained in $50 \mathrm{ml}$. flasks and were shaken at $35^{\circ}$.

$\begin{array}{ccccc}\text { Na L-glutamate } & \text { L-glutamine } & \begin{array}{c}\gamma \text {-L-glutamyl- } \\ \text { hydrazide }\end{array} & \begin{array}{c}\text { Additions to basal medium } \\ \text { with filaments } \\ \text { at Io hr }\end{array} & \begin{array}{c}\text { Morphological } \\ \text { form after }\end{array} \\ 0 & 0 & 0 & 7 & \text { Round } \\ 0.2 & 0 & 0.025 & 2 & \text { Round } \\ 0.2 & 0 & 0.050 & 4 & \text { Round } \\ 0.2 & 0 & 0 & >90 & \text { Rods } \\ 0 & 0.2 & 0.025 & >90 & \text { Rods } \\ 0 & 0.2 & 0.10 & >90 & \text { Rods } \\ 0 & 0.2 & 0 & >90 & \text { Rods }\end{array}$

At a molar ratio of $\mathrm{Na}$ L-glutamate : $\gamma$-L-glutamylhydrazide of about Io, complete inhibition of the transformation of the round forms was effected (Table 5). In other experiments inhibition occurred at ratios as high as about 50. Little or no inhibition of growth occurred at these ratios of $\mathrm{Na}$ L-glutamate to L-glutamylhydrazide, although no growth occurred at a ratio of about 2 . In the presence of L-glutamine, inhibition of neither growth nor morphological transformation occurred at a ratio of $2 \cdot 0$. Thus it seemed likely that the utilization of glutamine was of importance in changing the round forms to rods. 


\section{Effect of different concentration of $\mathrm{Na}$ L-glutamate and L-glutamine on rod-4}

It might be expected that, if L-glutamine is the active substance in effecting the change of the round form of the mutant into the rod-like form, then it would be functional at lower concentrations. On the other hand this might only be perceptible if the rate of synthesis of glutamine or the rate of penetration of glutamate into the organism were the limiting factors. If the lesion in the mutant involves the efficiency of the utilization of glutamine for one or more reactions within the organism, then an effect might not be seen. Also, if the mutant has an active glutaminase which rapidly hydrolyses glutamine into glutamic acid and ammonia, a difference might not be easily seen.

A small superiority of L-glutamine was shown both in the rate and degree of the permanence of the effect (Table 6). These effects were undoubtedly marginal; in several tests it was seen that whether or not the former was seen depended on readings being taken during the exponential phase of the change. There was no difference in the time of onset of the change (the lag phase) between cultures containing L-glutamine and those containing L-glutamate (Table 6).

Table 6. Bacillus subtilis I68: comparison of $\mathrm{Na}$ L-glutamate and L-glutamine in causing the round form to change into rod-4

The experiment was done as described in the text for the effect of L-amino acids on rod-4. Incubation was at $35^{\circ}$ with shaking.

\begin{tabular}{|c|c|}
\hline \multicolumn{2}{|c|}{$\underbrace{\text { Concentration }}_{(\%)}$} \\
\hline L-glutamate & L-glutamine \\
\hline 0.02 & 0 \\
\hline 0.10 & 0 \\
\hline 0.20 & 0 \\
\hline 0 & 0.02 \\
\hline 0 & 0.10 \\
\hline 0 & 0.20 \\
\hline 0 & 0 \\
\hline
\end{tabular}

$\begin{array}{rc}\begin{array}{r}\% \text { of round forms showing } \\ \text { filaments at hr: }\end{array} \\ \begin{array}{r}10.5 \\ 6\end{array} \\ 10 & 25 \\ 19 & 44 \\ 6 & 72 \\ 14 & 64 \\ 18 & 90-100 \\ <1 & 90-100 \\ & <1\end{array}$

$\begin{gathered}\text { Morphological } \\ \text { form after } \\ 24 \text { hr }\end{gathered}$
Round
Round
Rod
Round
Rod
Long rod
Round

\section{Effect of $\gamma$-L-glutamylhydrazide on parent strains}

The parent strain Bacillus subtilis 168 trp was grown on the $0.1 \%$ casein hydrolysate + minimal salts + glucose agar for $\mathrm{I} 8 \mathrm{hr}$, washed from the plate and washed once in the minimal liquid medium. This suspension was then inoculated into the minimal liquid medium supplemented with mixtures of Na L-glutamate, L-glutamine and $\gamma$-L-glutamylhydrazide exactly as in Table 5. Examination after $\mathrm{I} 8 \mathrm{hr}$ incubation at $35^{\circ}$ showed that there was an increase in the length of the bacilli with increasing concentration of $\gamma$-L-glutamylhydrazide in the presence of $\mathrm{Na} \mathrm{L}$-glutamate, but no such increase when the amino acid was replaced by L-glutamine. No rounding of the bacilli was seen although some of the long bacilli were twisted and bent. 


\section{DISCUSSION}

L-Glutamine formed from L-glutamic acid seems likely to be the major, if not the only, factor concerned with changing this particular mutant from a round form to a rod, at least in liquid growth media. High ionic strengths simply rendered much lower concentrations of sodium glutamate effective. The change effected on solid media by high salt concentration alone may well have been due to the presence of small amounts of amino acid in the agar medium. This enhancement of the effect of glutamate may have several explanations which, in terms of simplicity, range from a decrease of the surface forces needed to make a rod as compared with those needed to make a sphere by osmotic support, through possible effects on the permeation of glutamate into the bacillus, up to sophisticated effects of salt on the enzymes involved in glutamate and glutamine metabolism. The latter type of effect would be akin to the osmotic remedying of mutations previously referred to (Rogers et al. 1968, 1970). At present we have no evidence from which to distinguish these possibilities.

A disturbance in the metabolism of glutamine might be expected to lead to widespread effects within the bacteria. Glutamine is known to be involved in the biosynthesis of purines, of pyrimidines, of folic acid and of amino sugars (see Meister, 1965, for a summary of these reactions); these compounds are concerned with vital cell structures. Also, an exceptionally high proportion of the carboxyl groups of membrane proteins is amidated (Maddy \& Malcolm, I965; Wallach \& Zahler, 1968) and about $50 \%$ of the free $\alpha$-carboxyl groups of the D-glutamic acid in the mucopeptides of bacilli are probably amidated (Hughes, Pavlik, Rogers \& Tanner, 1968; Mirelman \& Sharon, 1968). Abnormalities in the fine structure in the walls, in the arrangement of the membranes and possibly in the DNA have been seen (Rogers et al. 1970) with the electron microscope in sections of the mutant. All these structures have components likely to be dependent on L-glutamine for their formation. However, although an analogue of L-glutamine ( $\gamma$-L-glutamylhydrazide) can prevent glutamic acid from correcting the morphology of the mutant, it is not itself capable of causing abnormality in the parent, although it appears to some extent to interfere with division.

Two aspects of the disturbance in the mutant can be distinguished. The first is that in the presence of glutamic acid or glutamine, long filamentous forms were produced with regularity on solid media. These filaments appeared to be made up of individuals 5 to Io times longer than those in the parent strain and were joined to form very long threadlike forms. These threads subdivided differently according to the supply of the amino acid. When the concentration was high (i.e. 0.1 to $0.2 \%$ in media of low ionic strength) then the final length of most of the forms was like the bacteria in the parent strain. When the concentration was low (0.05\% or less), subdivision continued and the walls swelled until more or less spherical organisms were formed. When the mutant was growing on solid media, the final result was like a string of beads. Thus one disturbance in the rod mutant was clearly connected with the process of division, which appeared to be partially inhibited while a sufficient supply of L-glutamine was available. This situation is reminiscent of that reported by Walker \& Pardee (1967) for the lon mutant of Escherichia coli $\mathrm{K}_{\mathrm{I}} 2 \mathrm{~F}^{-}$strain AB I $899 \mathrm{NM}$. This mutant formed filaments after irradiation when grown on a yeast + peptone medium, but divided to form normal length bacteria when transferred to a minimal medium. Multiple septation of some cells of Bacillus cereus ATCC 4342 has also been observed (Pfister \& Lundgren, 
Journal of General Microbiology, Vol. 6I, No. 2

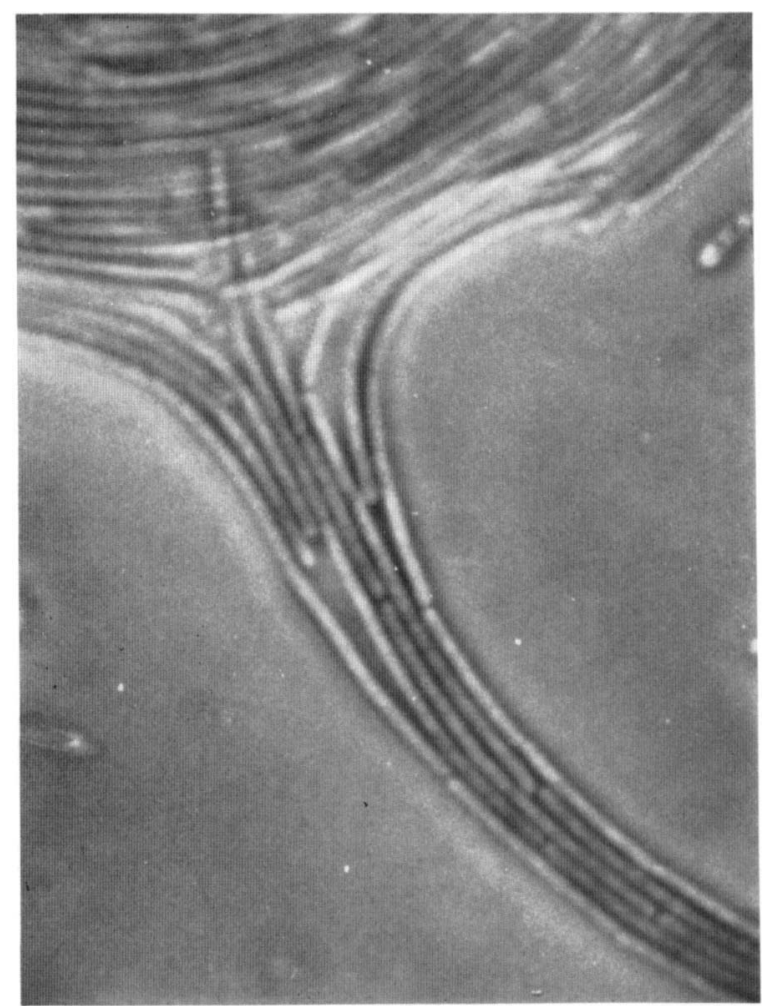

Fig. 1

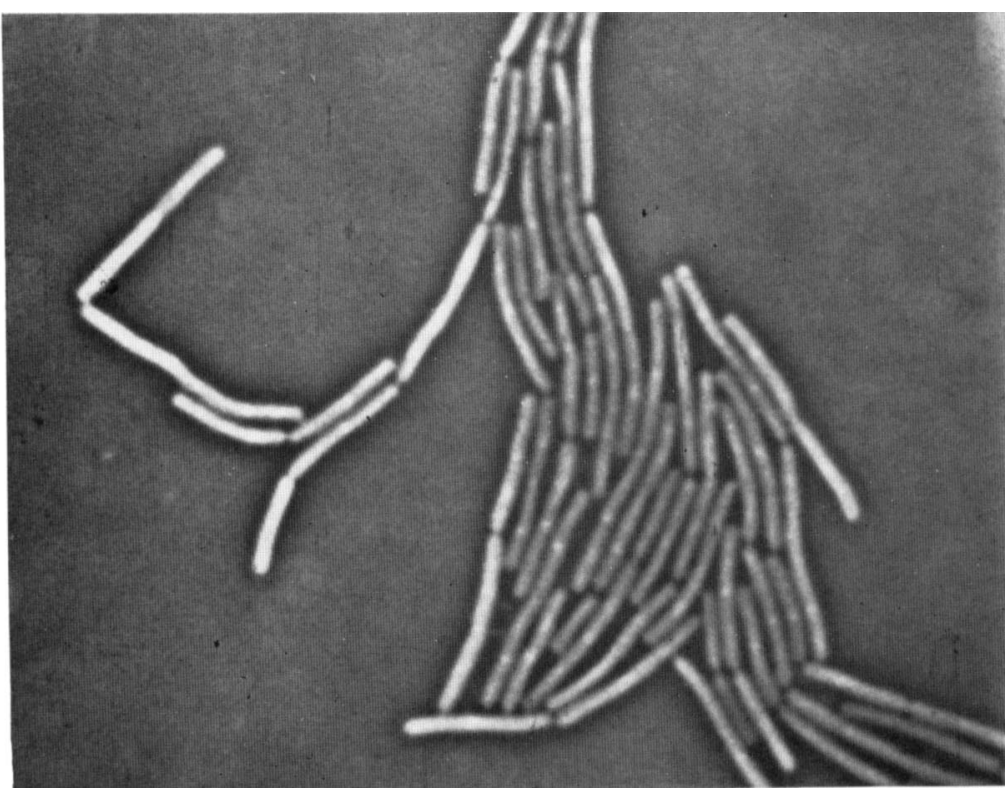

Fig. 2

H. J. ROGERS AND M. MCCONNELL
Plate I

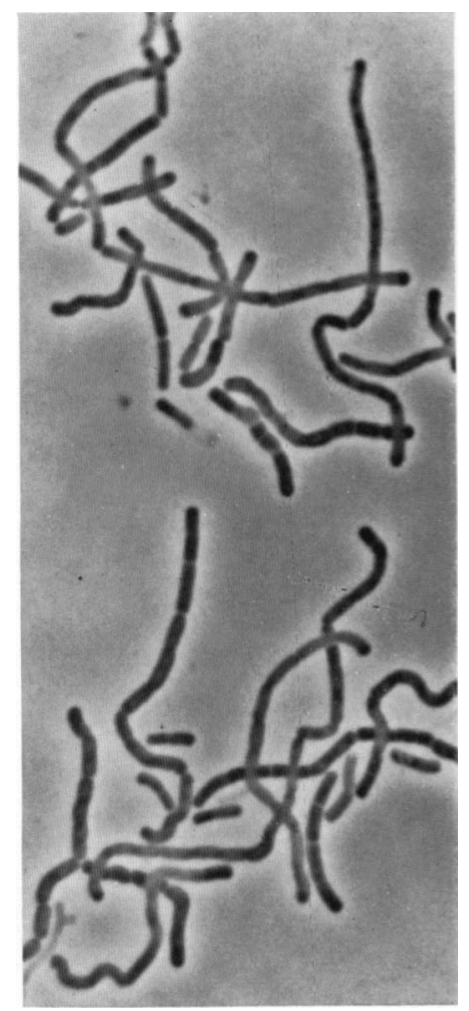

Fig. 3

(Facing p. 18I) 
1964; Remsen \& Lundgren, I965) in cultures undergoing sporulation and therefore likely to have been in some ways nutritionally deficient. These observations ought to be thought about in relation to the normal lengthening of cells that occurs at faster growth rates on richer media (Schaechter, Maaløe \& Kjeldgaard, 1958). All these phenomena may be related to the regulation of the formation of a division protein.

The second disturbance in the rod mutants was concerned with the nature of the walls of the organism when growing in the coccal form. It would appear that these were weak and bulged when the bacteria were deficient in their supply of glutamine. This weakness is consistent with the presence of a relatively uncrosslinked mucopeptide in the wall as compared with that in the rod-like form of the mutant (Rogers, McConnell \& Hughes, to be published).

\section{REFERENCES}

Hughes, R. C., Pavlik, J. G., Rogers, H. J. \& Tanner, P. J. (1968). Organization of polymers in the cell walls of some bacilli. Nature, London 219, 642.

MAdDY, A. H. \& MALCOLM, B. R. (1965). Protein conformations in the plasma membrane. Science, New York 150, 1616.

McIlwain, H., Roper, J. A. \& Hughes, D. E. (1948). Relationships in streptococci between growth and metabolism of glutamine. Biochemical Journal 42, 492.

Meister, A. (1965). In Biochemistry of the Amino Acids (2nd ed.), vol. 2, p. 621. New York and London: Academic Press.

Mirelman, D. \& Sharon, N. (I968). Isolation and characterization of the disaccharide $N$-acetyl glucosaminyl- $\beta(\mathrm{I}-4) N$-acetyl muramic acid and two tripeptide derivatives of this disaccharide from lysozyme digests of Bacillus licheniformis ATCC 9945 cell walls. Journal of Biological Chemistry 243, 2279.

Pfister, R. M. \& LundGRen, D. G. (1964). Electron microscopy of polyribosomes within Bacillus cereus. Journal of Bacteriology 88, 1119.

RemSEN, C. C. \& LUNDGREN, D. G. (1965). Multiple septation in variants of Bacillus cereus. Journal of Bacteriology 90, 1426.

Rogers, H. J., McConnell, M. \& Burdett, I. D. J. (1968). Cell wall or membrane mutants of Bacillus subtilis and Bacillus licheniformis with grossly deformed morphology. Nature, London 219, 285.

Rogers, H. J., MCConnell, M. \& BURDetT, I. D. J. (1970). The isolation and characterization of mutants of Bacillus subtilis and Bacillus licheniformis with disturbed morphology and cell division. Journal of General Microbiology 6r, 155.

SChaEChTER, M., MAALøE, O. \& KJELDGAARD, N. O. (1958). Dependence on medium and temperature of cell size and chemical composition during balanced growth of Salmonella typhimurium. Journal of General Microbiology 19, 592.

WalkeR, J. R. \& PARDEe, A. B. (1967). Conditional mutations involving septum formation in Escherichia coli. Journal of Bacteriology 93, 107.

WALLACH, D. F. H. \& ZAHLER, P. H. (1968). Protein conformations in cellular membranes. Proceedings of the National Academy of Sciences of the United States of America 56, 1552.

\section{EXPLANATION OF PLATE}

Fig. I. Bacillus subtilis 168 trp rod-4 growing on nutrient agar as filaments and very long forms.

Fig. 2. A later stage of growth of the same culture as in fig. I with the very long forms subdividing to form rods.

Fig. 3. An $18 \mathrm{hr}$ culture of the parent strain (Bacillus subtilis $168 \mathrm{trp}$ ) growing on nutrient agar. 